\title{
Injeção subconjuntival de soro autóġeno no tratamento de queimadura ocular por álcali em coelhos
}

\author{
Subconjunctival injection of autogenous blood in the treatment of ocular alcali burn in \\ rabbits
}

\author{
Marcela Colussi Cypel ${ }^{1}$ \\ Denise Atique Goulard ${ }^{2}$ \\ Fabiana Amorim de Lima ${ }^{3}$ \\ Jonathan Clive Lake ${ }^{3}$ \\ Eliane Uesugui ${ }^{3}$ \\ Maria Cristina Nishiwaki-Dantas ${ }^{4}$ \\ Paulo Elias Correa Dantas ${ }^{5}$
}

\section{RESUMO}

Objetivo: Estudar a ação da injeção subconjuntival de soro autógeno na evolução das complicações, após queimadura ocular grave por álcali induzida experimentalmente em coelhos. Métodos: Foram utilizados trinta olhos de coelhos da raça Nova Zelândia, divididos em dois grupos, de 15 coelhos cada, ambos submetidos à queimadura grave por álcali. Em 15 olhos (grupo tratado), efetuamos, imediatamente após a queimadura, injeção de soro autógeno subconjuntival. Os resultados foram avaliados e comparados logo após a queimadura e nos dias $1,3,7,15$ e 30 por meio de ectoscopia biomicroscopia ocular. Resultados: O grupo tratado apresentou melhor resposta de reepitelização da córnea, na fase inicial do processo do que o grupo controle (grupo sem soro autógeno), diferença esta estaticamente significante, assim como resultado final com um menor número de complicações. Conclusão: Os resultados obtidos neste estudo experimental sugerem que soro autógeno pode ter efeito no processo de cicatrização dos olhos após queimadura alcalina, diminuindo complicações tardias e melhorando o prognóstico quanto à estabilidade do processo inflamatório cicatricial.

Descritores: Córnea/lesões; Álcalis/efeitos adversos; Queimaduras oculares/induzidas quimicamente; Injeções; Soluções oftálmicas/uso terapêutico; Cicatrização de feridas; Microscopia eletrônica; Coelhos

\section{INTRODUÇÃOO}

Queimaduras oculares são freqüentes e decorrem principalmente da manipulação inadequada de substâncias químicas. Evoluem comprometendo permanentemente a acuidade visual e a superfície ocular ${ }^{(1)}$.

As queimaduras por álcali se encontram no grupo das urgências oftalmológicas. Seu pronto reconhecimento e adequado tratamento são vitais na evolução e controle das complicações associadas, sejam precoces ou tar$\operatorname{dias}^{(1-2)}$.

A literatura descreve várias formas de tratamento para queimadura ocular por álcali, tais como lubrificantes artificiais ${ }^{(1)}$, inibidores da colagenase $^{(1)}$, lente de contato terapêutica ${ }^{(1)}$, aplicação tópica de fibronectina ${ }^{(1)}$, ${\text { vitamina } \mathrm{C} \text { e } \text { citrato }^{(2)} \text {, transplante de conjuntiva }}^{(1)}$, recobrimento com membrana amniótica humana ${ }^{(3)}$ e transplante de limbo ${ }^{(4)}$.

A injeção subconjuntival de soro autógeno parece ser uma alternativa, embora pouco difundida em nosso meio, talvez pela dificuldade de acesso e pouca divulgação das línguas em que estes estudos foram publicados (pesquisa bibliográfica realizada encontrou somente textos em Russo, Tcheco, Chinês e Polonês) $)^{(5-7)}$. Foi publicado um estudo ${ }^{(5)}$ em que a aplica- 
ção de sangue autógeno subconjuntival, após queimadura ocular, levou a menos simbléfaro e leucomas cicatriciais da córnea. Em 1969(6), publicaram estudo com 348 olhos, dos quais 172 receberam injeção subconjuntival de sangue e mostraram melhor acuidade visual final que o grupo controle.

Em $1973^{(7)}$, relataram 293 olhos submetidos à administração de sangue autógeno subconjuntival, como método terapêutico para queimaduras oculares químicas que apresentaram melhor acuidade visual.

O soro autógeno parece aumentar a regulação de Mucina1 nas culturas de células epiteliais conjuntivais ${ }^{(8)}$; talvez possua propriedade bactericida ${ }^{(2,9)}$, fatores de crescimento, vitamina $\mathrm{A}^{(1)}$ e citoquinas ${ }^{(8)}$ que podem auxiliar a suprir a deficiência da lágrima e interferir na manutenção da superfície ocu$\operatorname{lar}^{(8)}$.

Objetivamos estudar o efeito da ação da injeção subconjuntival de soro autógeno nas complicações após queimadura ocular por álcali, induzida experimentalmente em coelhos.

\section{MÉTODOS}

\section{Desenho do estudo}

Estudo experimental em coelhos, do tipo prospectivo, comparativo e duplo-cego.

\section{Seleção dos animais}

Foram utilizados 30 coelhos albinos, machos, da raça Nova Zelândia, pesando de 2 a $3 \mathrm{~kg}$. Os animais foram divididos, por sorteio, em dois grupos de 15 coelhos cada (grupo tratado e grupo controle), mantidos em gaiolas apropriadas, com alimentação e hidratação ad libitum e controle veterinário constante. As recomendações para manuseio de animais de pesquisa da Unidade de Técnica Cirúrgica e Cirurgia Experimental (UTECE / Santa Casa / SP), do Comitê Brasileiro para Experimentos em Animais de Laboratório (COBEA) e da Association for Research and Vision in Ophthalmology (ARVO) foram seguidas.

O protocolo deste estudo foi aprovado sem restrições pelo Comitê de Ética em Pesquisa da UTECE / Santa Casa / SP.

\section{Modelo experimental de queimadura ocular por álcali}

O modelo experimental realizado seguiu modelos já descri$\operatorname{tos}^{(10-11)}$, com modificação em relação à magnitude do disco de papel e à técnica da anestesia geral.

Provocamos queimadura ocular Grau III e IV (classificação de Huges, 1946 modificada por Ballen, 1964 e Roper-Hall, $1965)^{(12)}$ no olho direito de todos os coelhos. Os animais foram submetidos à anestesia geral. Após instilação de uma gota de colírio de proparacaína $1 \%$ nos olhos direitos, queimadura ocular por álcali foi provocada, colocando-se um disco de papel de filtro $\mathrm{n}^{\circ} 40$ (Whatman), de 12 mm de diâmetro, abrangendo córnea e o limbo justacorneal, embebido em hidróxido de sódio $(\mathrm{NaOH} 4 \mathrm{~N})$ durante um minuto.
Imediatamente após a queimadura, o olho era lavado com 1000 cc de solução de $\mathrm{NaCl}$ 0,9\%. Durante o mesmo ato anestésico, realizamos a coleta de $5 \mathrm{cc}$ de sangue venoso periférico de 15 coelhos (coelhos de números 1 a 15, grupo de estudo). O sangue foi centrifugado a $2500 \mathrm{rpm}$ durante 10 minutos, para obtenção do soro autógeno. Após a centrifugação, aspiramos 0,3 cc do soro e injetamos, com agulha de insulina, essa quantidade no espaço subconjuntival superior (12 horas) dos olhos do grupo de estudo. No grupo controle (15 olhos de 15 coelhos) injetamos $0,3 \mathrm{cc}$ de solução salina balanceada no espaço subconjuntival superior.

\section{Acompanhamento e exame dos animais}

Os animais foram acompanhados por 30 dias, e avaliados imediatamente após a queimadura e nos dias $1,3,7,15$ e 30 subseqüentes a ela. Os exames foram realizados por observador independente e constaram de ectoscopia e biomicroscopia com lâmpada de fenda manual portátil (Heine-HSL100, USA), após a instilação de colírio anestésico e de fluoresceína sódica. Realizamos registro vídeo-fotográfico de cada uma das avaliações com Filmadora Digital Sony modelo PC1- Japão, seguido de preenchimento de questionário pré-formulado. Nas respostas com opção $\underline{\operatorname{sim}}$ ou não (dados nominais), $\underline{\text { sim }}$ correspondeu a 1 ponto e não a 0 ponto; respostas com opção gradual (dados ordinais); o não correspondeu a 0 ponto, muito leve a 1 ponto, leve a 2 pontos, moderada a 3 pontos e grave a 4 pontos. Para as medidas horizontais e verticais, em milímetros, de desepitelização da córnea foram registrados os valores numéricos (dados contínuos).

Durante os primeiros 20 dias após a queimadura ocular (período de re-epitelização da córnea), ambos os grupos foram tratados com antibiótico tópico (ofloxacina 3\%) instilado 3 vezes ao dia e lágrima artificial sem preservante, instilada 3 vezes ao dia.

Foram sacrificados, antes do final do estudo, os coelhos que apresentaram perfuração ocular ou afinamento grave, com iminência de perfuração ocular, durante a evolução do processo.

Os resultados foram submetidos a estudo estatístico. Para as respostas ao questionário referentes a sim e não (dados nominais), aplicamos o teste do Qui-quadrado e o teste de Fisher. Para as respostas ao questionário referentes ao escore (dados ordinais) e referentes a desepitelização da córnea (dados contínuos), aplicamos o teste não-paramétrico de MannWhitney, sendo aceito, nos dois casos, como diferença estatisticamente significante, valores de $\mathrm{p}<0,05$.

\section{RESULTADOS}

Hiperemia conjuntival apresentou diferença estatisticamente significante no dia 1 , mais intensa no grupo que recebeu soro autógeno ( $p=0,012)$. Nos demais dias, não houve diferença estatisticamente significante entre os dois grupos.

A presença de secreção ocular não mostrou diferenças estatisticamente significativas entre os dois grupos em ne- 
nhum dos dias avaliados. Desde o dia 1 até o dia 30, encontrou-se secreção ocular purulenta ou mucóide em ambos os grupos com distribuição homogênea.

Não observamos diferença estatisticamente significante até o exame do dia 15 quanto ao simbléfaro e/ou sinéquia da pálpebra superior com a pálpebra inferior. No exame do dia 30, apesar de não haver diferença estatisticamente significante, o valor de $p$ ficou próximo do nível de significância $(p=0,074)$, tendo o grupo controle apresentado mais simbléfaro e/ou sinéquia das pálpebras.

O grupo tratado apresentou menor área de vascularização límbica imediatamente após a queimadura, diferença essa estatisticamente significante $(p=0,02)$. No dia 1 , essa diferença já não era significante $(p=1,00)$. Nova mudança foi observada no dia 3, quando todos os olhos do grupo de estudo apresentavam o limbo vascularizado em alguma região, enquanto no grupo controle ainda havia olhos com limbo avascular. Esta diferença se mostrou estatisticamente significante $(p=0,042)$. Nos dias 7, 15 e 30, não observamos diferença entre os grupos, pois ambos apresentavam alguma região do limbo vascularizada (Gráfico 1).

A conjuntivalização da córnea só se mostrou biomicroscopicamente perceptível a partir do $3^{\circ}$ dia de exame, mas diferença estatisticamente significante $(p=0,002)$ foi notada no $7^{\circ}$ dia de exame, quando o grupo de estudo, na sua maioria, apresentou córnea conjuntivalizada. No $15^{\circ}$ dia, apesar de haver diferença clínica considerável entre os grupos, não constatamos significância estatística. No dia 30, voltamos a encontrar maior

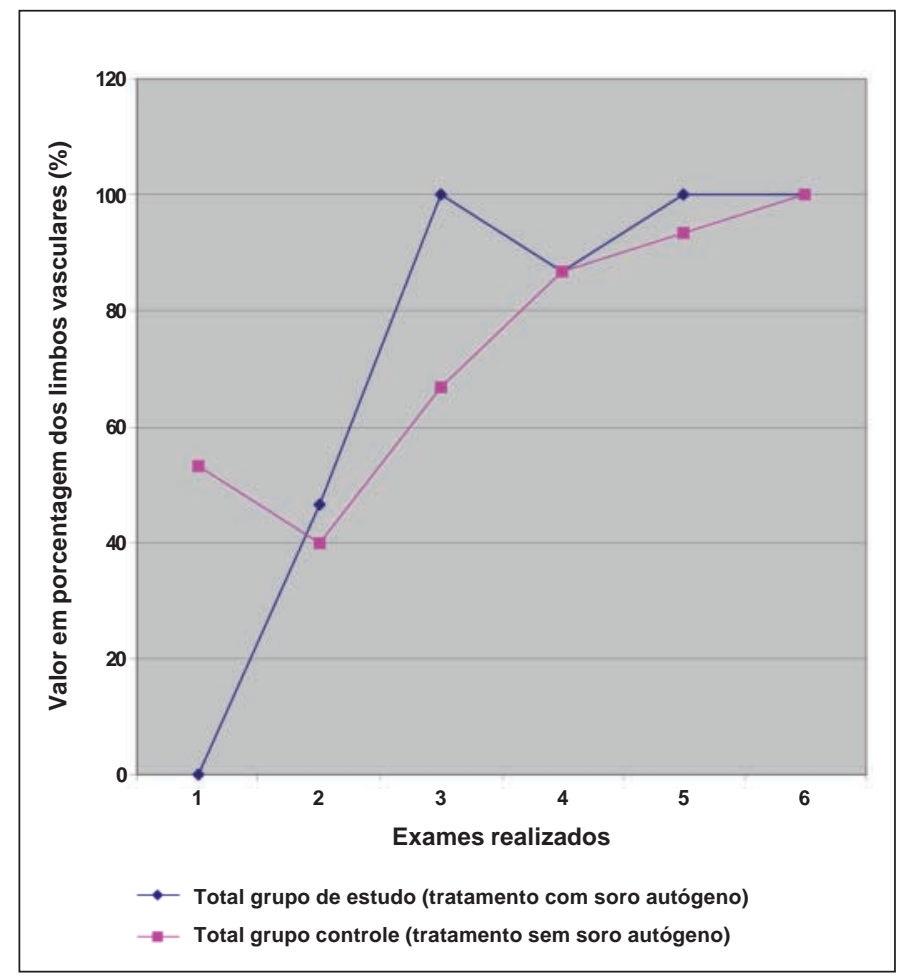

Gráfico 1. Evolução da vascularização do limbo nos coelhos após queimadura por álcali conjuntivalização no grupo de estudo, diferença estatisticamente significante $(p=0,009)$.

O grau de opacidade da córnea, computada como escore, não mostrou diferença estatística entre os grupos em nenhum dos dias da avaliação.

A tabela 1 mostra à desepitelização da córnea, imediatamente após a queimadura e nos dias 1, 3, 7, 15 e 30, acompanhados da média e do desvio padrão das lesões em cada dia. A cicatrização no sentido horizontal ficou próxima da significância no dia 1 ( $p=0,077)$ e significante no dia $3(p=0,001)$. O grupo em estudo apresentou diminuição do tamanho da lesão no sentido horizontal mais rapidamente que o grupo controle apenas neste dia. Já nos outros dias, não encontramos diferença estatisticamente significante. A cicatrização no sentido vertical mostrou diferença estatisticamente significante nos dias $3(p=0,006)$ e 7 ( $p=$ 0,037 ) e novamente no grupo de estudo ela mostrou-se mais rápida. Quando analisada a área desepitelizada e em reepitelização (medida horizontal x medida vertical), encontrou-se diferença estatisticamente significante no dia 3 ( $p=0,002)$, mostrando que, considerando-se a área da lesão, o grupo em estudo, num primeiro momento, re-epitelizou significativamente mais rápido que o grupo controle (Tabela 1).

Em relação à presença de afinamento da córnea, que se mostrou presente desde o exame do dia 15 , só notamos diferença com significância estatística no dia $30(p=0,09)$, quando o grupo controle apresentou maior afinamento da córnea do que o grupo de estudo (Gráfico 2).

Os coelhos nํㅗ 3 e 20 foram sacrificados no décimo nono dia após a queimadura, pois, evoluíram com afinamento corneal importante, seguido de perfuração ocular. O coelho $\mathrm{n}^{\circ} 1$ foi sacrificado no vigésimo primeiro dia após queimadura, por possuir afinamento grave da córnea, em iminência de perfuração ocular.

\section{DISCUSSÃO}

A presença de maior intensidade de hiperemia conjuntival no grupo de coelhos que receberam soro autógeno por via subconjuntival, mostrando diferença estatisticamente significante em relação ao grupo controle, no exame do dia 1 , poderia estar associada à possível ação irritante local do soro, já que nos dias subseqüentes não notamos diferença.

Com relação à re-epitelização da córnea, partimos de dois grupos com lesões semelhantes (em tamanho e grau de opacidade corneal), porém da fase inicial até apenas o sétimo dia de observação, notamos maior velocidade de cicatrização no grupo tratado. É possível que o soro autógeno e seus componentes atuem de maneira mais efetiva nos primeiros dias, em razão de sua maior quantidade e concentração no espaço subconjuntival. O soro sanguíneo apresenta substâncias como macroglobulinas e inibidores da colagenase I que, numa fase tardia de reparo após a queimadura grave, provêm dos vasos limbares ou dos vasos neoformados da córnea ajudando a diminuir a reação inflamatória e a necrose local ${ }^{(1)}$. Em nosso 


\begin{tabular}{|c|c|c|c|c|c|}
\hline & $\begin{array}{c}\text { Média } \\
\text { grupo de estudo }\end{array}$ & $\begin{array}{l}\text { Desvio padrão } \\
\text { grupo de estudo }\end{array}$ & $\begin{array}{c}\text { Média } \\
\text { grupo controle }\end{array}$ & $\begin{array}{l}\text { Desvio padrão } \\
\text { grupo controle }\end{array}$ & $\mathbf{p}^{*}$ \\
\hline $\mathrm{HO}$ & 11,73 & 1,70 & 11,40 & 1,59 & 0,483 \\
\hline V0 & 10,46 & 0,91 & 10,13 & 1,40 & 0,173 \\
\hline $\mathrm{H} 1$ & 10,53 & 1,18 & 11,26 & 0,88 & 0,077 \\
\hline V1 & 8,46 & 1,24 & 8,80 & 0,77 & 0,116 \\
\hline $\mathrm{H} 3$ & 5,96 & 2,07 & 8,53 & 1,64 & 0,001 \\
\hline V3 & 5,40 & 1,59 & 7,06 & 1,27 & 0,006 \\
\hline $\mathrm{H} 7$ & 5,13 & 2,16 & 5,10 & 2,08 & 0,566 \\
\hline V7 & 4,53 & 1,72 & 5,96 & 2,07 & 0,037 \\
\hline $\mathrm{H} 15$ & 2,53 & 2,41 & 3,13 & 2,38 & 0,468 \\
\hline V15 & 2,00 & 1,92 & 2,60 & 2,06 & 0,337 \\
\hline $\mathrm{H} 30$ & 1,27 & 2,00 & 1,00 & 1,33 & 0,935 \\
\hline V30 & 1,18 & 1,77 & 0,80 & 1,03 & 0,745 \\
\hline HOVO & 124,07 & 28,38 & 117,07 & 31,07 & 0,219 \\
\hline H1V1 & 89,93 & 21,07 & 99,47 & 13,82 & 0,092 \\
\hline H3V3 & 34,80 & 18,08 & 61,87 & 19,72 & 0,002 \\
\hline H7V7 & 26,27 & 15,09 & 32,70 & 17,45 & 0,370 \\
\hline H15V15 & 9,33 & 9,85 & 12,60 & 11,57 & 0,340 \\
\hline H30V30 & 4,33 & 8,43 & 2,00 & 2,53 & 0,808 \\
\hline
\end{tabular}

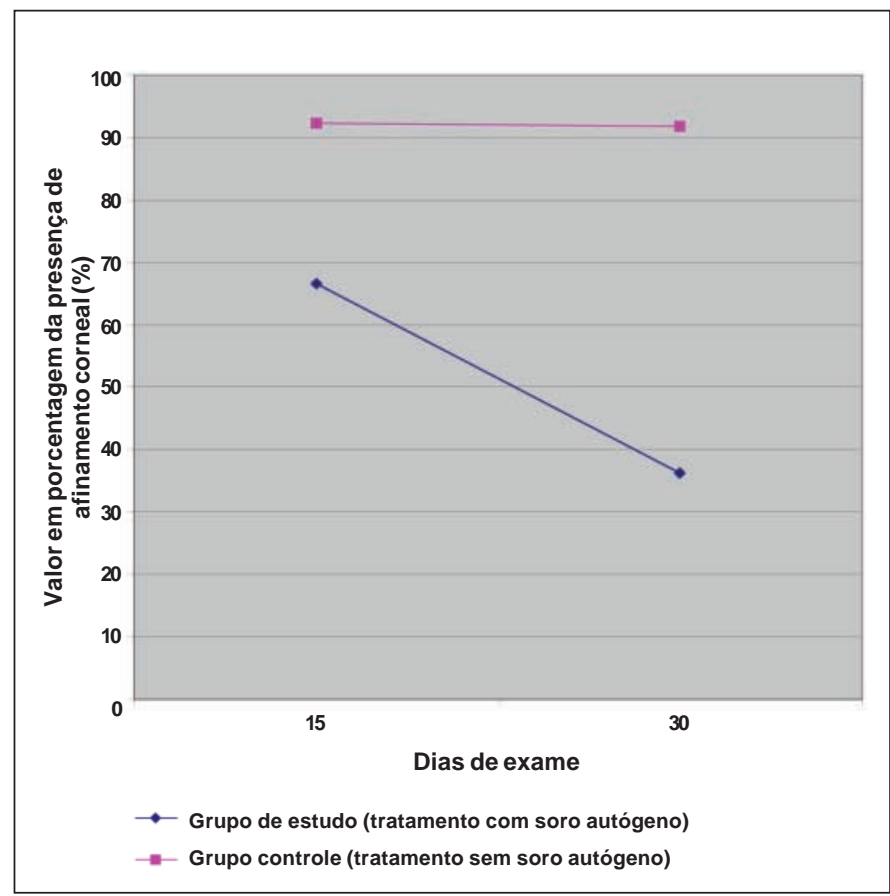

Gráfico 2 - Presença de afinamento corneal nos coelhos após queimadura por álcali - UTECE / Santa Casa / São Paulo - 08/2001

estudo, ao injetarmos o soro autógeno subconjuntival, fornecemos tais substâncias numa fase mais precoce, na tentativa de manter este processo rapidamente controlado. Talvez, um número maior ou mais freqüente de aplicações de soro autógeno ou a associação de medidas terapêuticas (medicamentosas ou cirúrgicas), possam dar caráter adjuvante ao uso de soro autógeno no tratamento de queimaduras oculares agudas.

O comentário acima é reforçado pelo fato dos coelhos do grupo de estudo, no exame imediato, apresentarem $100 \%$ de limbo avascular e, já no dia 3, apresentarem número maior de limbos vascularizados. A melhora na fase inicial, mais rápida no grupo de estudo, pode ter sido responsável pela apresentação biomicroscópica com menos complicação na fase tardia do acompanhamento.

A comparação entre os dados encontrados neste estudo e os relatados por outros autores ${ }^{(1,5-6)}$ torna-se difícil, uma vez que os trabalhos são escassos, de difícil compreensão, não são experimentais e não fornecem detalhes do método utilizado (aplicação de sangue ou soro, quantidade de aplicação e forma de aplicação), além de apresentarem critérios de avaliação divergentes entre si (acuidade visual e tempo de hospitalização). Em 1973(7), sugerem como hipóteses para a ação do sangue subconjuntival: efeito mecânico, afastando a conjuntiva lesada da esclera; infiltração rápida removendo substâncias nocivas e material tóxico; fornecimento de substâncias nutritivas para o tecido prejudicado e efeito fibrinolítico ${ }^{(2)}$.

\section{CONCLUSÃO}

Os resultados obtidos sugerem que o soro autógeno pode ter efeito modulador no processo de cicatrização dos olhos após queimadura alcalina, diminuindo complicações tardias e melhorando o prognóstico da estabilidade do processo inflamatório cicatricial nas condições propostas. 


\section{ABSTRACT}

Purpose: To determine the activity of subconjunctival injection of autogenous serum in the treatment of ocular alkali burn induced experimentally in rabbits. Methods: Thirty eyes of 30 New Zeland albino rabbits were divided into two groups of 15 and submitted to ocular alkali burn. One group (treated group) received immediately after the alkali burn a subconjunctival injection of autogenous serum. The results were compared and recorded immediately after the alkali burn and on days 1 , $3,7,15$, and 30 by external ocular examination and manual portable slit lamp. Results: The treated group presented a better reepithelialization of the cornea than the control group, in the beginning of the process, with a statistically significant difference; and a final result with less complications, in the study group. Conclusion: The results obtained in this experimental study suggest that the autogenous serum may have a primary effect on the process of scarring of the eyes after ocular alkali burn, decreasing late complications and improving the prognosis related to the stability of the inflammatory scarring process.

Keywords: Cornea/injuries; Alkalies/adverse effects; Eye burns/chemically induced; Injections; Ophthalmic solutions/therapeutic use; Wound healing; Microscopy, electron; Rabbits

\section{REFERÊNCIAS}

1. Wagoner MD. Chemical injuries of the eye: current concepts in pathophisiology and therapy. Surv Ophthalmol. 1997;41(4):275-313.

2. Bechara SJ, Garcia IA, Kobinger E, Rodrigues CJ, José NK, Caldeira JAF. Uso simultâneo de acetil-cisteína e vitamina $C$ na terapêutica das queimaduras corneanas por álcali. Arq Bras Oftalmol. 1986;49(4):109-11.

3. Joseph A, Dua HS, King AJ. Failure of aminiotic membrane transplantation in the treatment of acute ocular burns [commented on $\mathrm{Br} \mathrm{J}$ Ophthalmol. 2002;86(7):831]. Br J Ophthalmol. 2001;85(9):1065-9.

4. Nishiwaki-Dantas MC, Dantas PEC, Reggi JRA. Ipsilateral limbal translocation for treatment of partial limbal deficiency secondary to ocular alkali burn. Br J Ophthalmol. 2001;85(9):1031-3.

5. Trusov MS, Rozenkrats KB. Surgical treatment of chemical burns of the eye in combination with irrigation with defibrinated blood and subconjunctival administration of autoblood with antibiotics. Vestn Oftalmol. 1966;79(1):61-5.

6. Kuprianowicz W, Czesnel H. Results of treatment of calcium eye burns with subconjunctival injections of blood. Klin Oczana. 1969;39(1):51-4.

7. Dolezalová V, Kustková L. Subconjunctival injection of autogenous blood in the eye after thermical and chemical burns. Cesk Oftalmol. 1973;29(3):207-12.

8. Nelson JD. Much more than water. Br J Ophtalmol. 1999;83(4):384-5. Commented on: Br J Ophthalmol. 1999;83(4):390-5.

9. Fox RI, Chan R, Michelson JB, Belmont JB, Michelson PE. Beneficial effect of artificial tears made with autologous serum in patients with keratoconjuntivitis sicca. Arthritis Rheum. 1984;27(4):459-61.

10. Sangwan SV, Akpek EK, Voo I, Zhao T, Pinar V, Yang J, et al. Krill protease effects on wound healing after corneal alkali burn. Cornea. 1999;18(6):707-11.

11. Siganos CS, Frucht-Pery J, Muallem MS, Berenshtein E, Naoumidi I, EverHadani P, et al. Topical use of zinc desferrioxamine for corneal alkali injury in a rabbit model. Cornea. 1998;17(2):191-5.

12. Lima ALH, Nishiwaki-Dantas MC, Alves MR. Córnea. In: Lima ALH, Nishiwaki-Dantas MC, Alves MR. Doenças externas oculares. Rio de Janeiro: Cultura Médica; 1999. p.390.

\section{CONGRESSO BRASILEIRO DE OFTALMOLOCIA}

\section{3 a 6 de Selembro de 2005 Centro de Convençöes de Fortalezca - CE}

INFORMAÇÕES: ARX Produções e Eventos

Tel.: (85) 272-1572

E-mail: cbo2005@arxweb.com.br Home-page: www.cbo2005.com.br 